\title{
Dr Narendradas Jayaratnam Walloopillai
}

FRCP(Lond), FRCP Cardiology (Edin), FACC

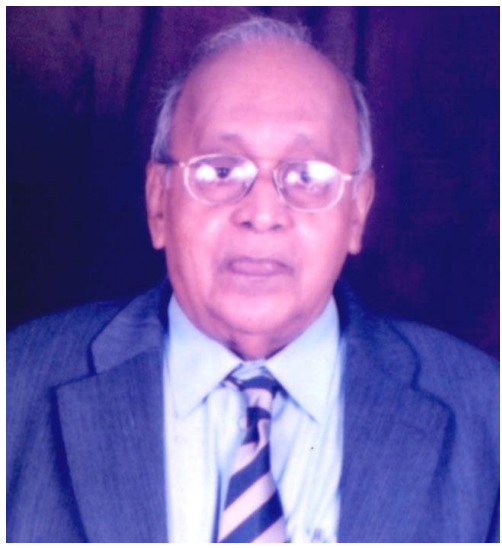

With deep sorrow I record the death of Dr $\mathrm{N} \mathrm{J}$ Walloopillai who passed away in his 85 th year, on the 6th of February 2011. This appreciation highlights some aspects of his life with special focus on his pioneering role in the Cardiac Investigation Unit and later in the Cardiology Institute of the National Hospital of Sri Lanka.

Dr Walloopillai was born to the influential and wealthy Velupillai family in Balangoda. He had his early education at St. Thomas' College, Mount Lavinia. It is interesting to note that when he was admitted to this school the Warden, Canon De Saram, changed the spelling of his name from Velupillai to Walloopillai saying that this was more user friendly. Consequently Velu became Walloo, a name his friends used when they addressed him.

Dr Walloopillai graduated from the Faculty of Medicine University of Ceylon in 1951. He proceeded soon after to the United Kingdom where he obtained his MRCP (Lond.) and MRCP Cardiology (Edinburgh) in 1954. He had his training in cardiology at Manchester.

On his return to Sri Lanka he was appointed Consultant Physician, General Hospital ,Jaffna and later assumed duties as the Physician in Charge of the Cardiac Investigation Unit, General Hospital, Colombo. He had Dr Mahinda Weerasena, Consultant Radiologist in his team. I joined them a few months later, with the establishment of the Cardiothoracic Unit. The three of us became very close friends and met frequently in our homes. Whenever I was away on leave Wallo would act for me in the Surgical Intensive Care Unit. When Dr Ivor Obeysekera retired, Dr Walloopillai was appointed Physician-in-Charge of the Cardiology Institute.

During Dr Walloopillai's tenure, cardiology came into its own as a speciality in this country. The Coronary Care Unit (CCU) which was founded by him in 1975 was the only one of its kind in Sri Lanka. Apart from the Surgical Intensive Care Unit (SICU) there were no other Intensive units in this country at that time. A large portion of the adjoining Church land was gifted to the Cardiology Unit at the request of the then Prime Minister Mrs Sirima Bandaranaike. This enabled the Cardiology Unit to be expanded further.

Dr Walloopillai was President of the Sri Lanka Medical Association in 1980 and President of the Sri Lanka Heart Association for several years. In addition, he was the President of the Orchid Circle, and in his beautiful home he had an exquisite collection of orchids which he tended with great care. He shunned large social gatherings, usually attending only those which he could not avoid. It is not generally known, but despite his somewhat shy nature he was an active trade unionist and was the President of the Association of Medical Specialists. Dr Walloopillai was always updating himself in Cardiology, and was an avid reader of scientific journals even in his twilight years. His charming wife predeceased him. At his request, Dr N J Walloopillai had a private funeral.

I end this appreciation with the final message Dr Walloopillai left for us. It embodies his philosophy and views on life and death.

"When I am gone, release me, let me go, be happy that we had so many years.

I have given my love, you can only take my word.

But now its time to travel alone to be at peace".

A T W P Jayawardene, Past President, SLMA 